\title{
Hospital Charges and Continuity of Care for Outpatients with Hypertension in South Korea: A Nationwide Population- Based Cohort Study from 2002 to 2013
}

\author{
Jae-Hyun Kim ${ }^{1,2}$, Eun-Cheol Park ${ }^{3,4}$, Tae Hyun Kim ${ }^{3,5}$, Yunhwan Lee $e^{6,7, *}$ \\ ${ }^{1}$ Department of Health Administration, Dankook University College of Health Science, Cheonan, Korea \\ ${ }^{2}$ Institute of Health Promotion and Policy, Dankook University, Cheonan, Korea \\ ${ }^{3}$ Institute of Health Services Research, Yonsei University, Seoul, Korea \\ ${ }^{4}$ Department of Preventive Medicine, Yonsei University College of Medicine, Seoul, Korea \\ ${ }^{5}$ Deprtment of Hospital Management, Yonsei University Graduate School of Public Health, Seoul, Korea \\ ${ }^{6}$ Department of Preventive Medicine and Public Health, Ajou University School of Medicine, Suwon, Korea \\ ${ }^{7}$ Institute on Aging, Ajou University Medical Center, Suwon, Korea
}

Background: Continuity of care (COC) has received attention over the past decade. COC has also become increasingly important for hospital managers and policy makers because of competitive health care market conditions. The purpose of this study was to assess the association between hospital charges and patients' continuity of careassessed by three indices of continuity of care-among outpatients with hypertension in South Korea.

Methods: This study used the National Health Insurance Service-Cohort Sample Database from 2002 to 2013. A total of 247,125 participants were analyzed at baseline (2002); continuity of care was defined using the continuity of care index, the Herfindahl-Hirschman index (a new continuity of care index), and the "most frequent provider continuity" index. Primary analyses were based on the generalized estimating equation regression model, which accounts for correlation among individuals within each hospital.

Results: After adjustment for age, sex, residential region, patient clinical complexity level, diagnosed code, hospital type, organization type, number of beds, number of doctors, and year, there was a negative correlation between hospital charges and continuity of care index $(\beta=-0.163, P<0.0001)$, the Herfindahl-Hirschman index $(\beta=-0.105$, $\mathrm{P}<0.0001)$, and the "most frequent provider continuity" index $(\beta=-0.131, \mathrm{P}<0.0001)$. Subgroup analyses based on hospital type produced similar trends.

Conclusion: For all indices studied, hospital charges declined gradually with increasing continuity of care. Our study suggests that long-term, trusting partnerships between patients and physicians reduce hospital costs.

Keywords: Hospitals; Continuity of Patient Care 


\section{INTRODUCTION}

Continuity of care (COC) has received attention over the past decade. Defined as a sustained partnership between patient and physician, COC is considered a core element reflecting high-quality care and patient satisfaction. ${ }^{1-3)}$ It contributes to improved patient adherence and self-management, ${ }^{3)}$ improved health outcomes, ${ }^{4)}$ and lower healthcare utilization and costs. ${ }^{5}$ It is assumed that patients who maintain COC relationships with their physicians care more about their health than those who do not maintain such relationships.

COC encourages strong physician-patient affiliation, trust, and communication, ${ }^{6)}$ with the physician accumulating knowledge of the patient's history and values. It also instills in the patient a sense of clinical self-responsibility, allowing physicians to provide better care at a lower cost. ${ }^{7,8)} \mathrm{COC}$ has also become increasingly important for hospital managers and policy makers, because the healthcare industry in South Korea is becoming more competitive. As patients can now choose from a wide range of providers, many hospitals have been forced to compete with each other for a larger share of the market, regardless of the size of the hospital. It is becoming vital to the long-term financial performance of hospitals in competitive markets to sustain relationships between physicians and patients by providing highquality care. If physicians do not meet the needs of patients effectively and efficiently, providers will be at risk of losing market share, and their viability will be threatened.

Many studies have found that those with higher COC use fewer resources and have lower healthcare costs. Furthermore, the association is stronger in the case of inpatients than in that of outpatients, suggesting that the main benefit of COC is that it reduces emergency department visits ${ }^{9,10)}$ and hospitalizations. ${ }^{5,11)}$

Thus, to ensure their long-term success and survival, it is important that hospitals retain and expand their regular patient base through high COC. Moreover, Zeithaml et al. ${ }^{12)}$ suggested that when patients assess positively service quality, it leads to desirable behavioral intentions, further strengthening their relationship with the physician. In the competitive healthcare market of South Korea, measuring each patient's COC within the hospital as a major source of competitive advantage is an important business strategy.

This study examined the association between COC and hospital charges among outpatients with hypertension in hospitals in South Korea. Hypertension is an important independent risk factor for cardiovascular events, which are a major cause of death. ${ }^{13)}$ Furthermore, patients with hypertension tend to visit healthcare institutions on a regular basis to receive prescriptions and education for blood pressure management, making them ideal subjects to observe the patient-physician relationship.

\section{METHODS}

\section{Data Sources and Study Design}

This study used the National Health Insurance Service-Cohort Sample
Database (NHIS-CSD) from 2002 to 2013, which has been released by the Korean National Health Insurance Service (KNHIS) ${ }^{14)}$ The initial NHIS-CSD cohort $(n=1,025,340$-approximately $2.2 \%$ of the entire population in 2002) was established by stratified random sampling using a systematic sampling method to generate a representative sample of the 46,605,433 South Korean residents recorded in 2002 . We excluded non-citizens and special-purpose employees with an unidentifiable income level. The baseline cohort members were followed for 11 years until 2013, unless they were disqualified due to death or emigration.

The healthcare utilization claims include information on prescription drugs, medical procedures, diagnostic codes based on the International Classification of Diseases, tenth revision (ICD-10), and healthcare costs. Detailed methods for establishing and ensuring the representativeness of the NHIS-CSD cohort have been published on the KNHIS website. ${ }^{14)}$

To analyze the relationship between COC and hospital charges among outpatients with hypertension, we isolated outpatients with the ICD-10 codes I10-I15 (hypertensive diseases) as their main diagnosis. We then linked each outpatient with hypertension to a particular hospital using a separate hospital licensing database that contains information arranged by calendar years. This linkage between outpatients and hospitals allowed us to investigate our hypothesis in a 12year follow-up.

\section{Study Variables: Independent Variables}

\section{1) Continuity of care index}

The COC index emphasizes the distribution of visits to each hospital that the patient visited. ${ }^{15)}$ One of the advantages of the COC index is that it reflects the co-ordination of care that occurs when one provider refers a patient to another provider and then receives the patient's referral again. The COC index measures the concentration or diversity of visits among all providers. Interestingly, for a given visit distribution, the COC index tends to increase as the total number of visits increases. However, the index is not affected by the sequencing of visits.

$$
\begin{aligned}
& \left(\sum_{j=1}^{M} n_{i}{ }^{2}-N\right) / N(N-1) \\
& \text { N=total number of outpatient visits } \\
& \mathrm{n}_{\mathrm{j}}=\text { number of visits to provider } \mathrm{j}
\end{aligned}
$$

\section{2) Herfindahl-Hirschman index}

The Herfindahl-Hirschman index (HHI-a new COC) was initially proposed by Zwanziger et al. ${ }^{16)}$ to measure market concentration using the sum of the squares of discharges from a disease category, viewed as a proportion of all discharges from the hospital. The present study measured the concentration of each patient per hospital. To investigate each patient's COC, we considered that having a narrower mix tends to cause an increase in the patient's COC in the hospital visited. 
HHI $($ New COC $)=\sum_{i=1}\left(P_{i}^{2}\right)$

$P_{i}=$ proportion of the number of each hospital visits accounted for by the ith hospital

\section{3) Most frequent provider continuity index}

The "most frequent provider continuity" (MFPC) index ${ }^{17)}$ primarily measures the concentration of visits in the hospital most often seen. Its value is not affected by the distribution of visits to other providers, or by the sequence in which visits are made to different providers. The MFPC index is constant, because the proportion of visits to the most frequent provider does not change as the number of visits increases. In contrast, the $\mathrm{HHI}$ focuses on the concentration of visits across all hospitals, while the COC index integrates both aspects into a single metric. In terms of measurement method, the MFPC index is a similar concept to the HHI; however, it only focuses on the density of care from

Table 1. General characteristics of subjects included for analysis at baseline (2002)

\begin{tabular}{|c|c|c|c|}
\hline Characteristic & Total & Hospital charges $\left(\mathrm{KRW}^{*}\right)$ & P-value \\
\hline \multicolumn{4}{|l|}{ Individual } \\
\hline Sex & & & 0.795 \\
\hline Male & $98,134(39.7)$ & $17,822 \pm 43,988$ & \\
\hline Female & $148,991(60.3)$ & $17,255 \pm 32,457$ & \\
\hline Age (y) & & & $<0.0001$ \\
\hline$\leq 39$ & 8,922 (3.6) & $23,396 \pm 84,760$ & \\
\hline $40-49$ & $38,780(15.7)$ & $16,748 \pm 40,645$ & \\
\hline $50-59$ & $67,844(27.5)$ & $16,475 \pm 37,555$ & \\
\hline $60-69$ & $80,610(32.6)$ & $17,436 \pm 33,797$ & \\
\hline $70-79$ & $24,980(10.1)$ & $18,642 \pm 27,753$ & \\
\hline$\geq 80$ & $25,989(10.5)$ & $18,182 \pm 20,808$ & \\
\hline Residential region & & & $<0.0001$ \\
\hline Metropolitan & $54,390(22.0)$ & $17,235 \pm 32,936$ & \\
\hline Urban & $67,002(27.1)$ & $17,821 \pm 41,391$ & \\
\hline Rural & $125,733(50.9)$ & $17,404 \pm 37,100$ & \\
\hline Patient clinical complexity level & & & - \\
\hline 0 & $247,125(100.0)$ & $17,480 \pm 37,464$ & \\
\hline 1 & - & - & \\
\hline$\geq 2$ & - & - & \\
\hline Diagnosed code (110-I15) & & & $<0.0001$ \\
\hline Essential hypertension & $211,157(85.5)$ & $16,562 \pm 19,606$ & \\
\hline Hypertensive heart disease & $27,238(11.0)$ & $17,100 \pm 19,963$ & \\
\hline Hypertensive renal disease & $1,842(0.8)$ & $116,053 \pm 350,229$ & \\
\hline Hypertensive heart and renal disease & $4,727(1.9)$ & $19,321 \pm 22,229$ & \\
\hline Secondary hypertension & $2,161(0.9)$ & $23,895 \pm 62,722$ & \\
\hline \multicolumn{4}{|l|}{ Hospital } \\
\hline Type & & & $<0.0001$ \\
\hline General hospital & $31,176(12.6)$ & $29,969 \pm 94,264$ & \\
\hline Hospital & $4,991(2.0)$ & $22,389 \pm 61,009$ & \\
\hline Clinic & $210,958(85.4)$ & $15,518 \pm 14,681$ & \\
\hline Organization type & & & 0.334 \\
\hline Public & $924(0.4)$ & $21,940 \pm 28,839$ & \\
\hline Private & $246,201(99.6)$ & $17,463 \pm 37,492$ & \\
\hline Bed & & & $<0.0001$ \\
\hline$\leq 99$ & $212,951(86.2)$ & $15,572 \pm 16,879$ & \\
\hline $100-199$ & $2,379(1.0)$ & $22,571 \pm 30,838$ & \\
\hline 200-299 & $2,085(0.8)$ & $20,761 \pm 29,952$ & \\
\hline$\geq 300$ & $29,710(12.0)$ & $30,518 \pm 96,411$ & \\
\hline Doctor & & & $<0.0001$ \\
\hline$\leq 49$ & 220,929 (89.4) & $15,924 \pm 17,947$ & \\
\hline $50-99$ & $2,128(0.9)$ & $23,050 \pm 41,079$ & \\
\hline $100-149$ & $5,470(2.2)$ & $21,449 \pm 34,683$ & \\
\hline$\geq 150$ & $18,598(7.5)$ & $34,156 \pm 118,165$ & \\
\hline Total & $247,125(100.0)$ & $17,480 \pm 37,464$ & \\
\hline
\end{tabular}

Values are presented as number (\%) or mean \pm standard deviation.

*1 United States dollar=approximately 1,200 Korean won. 
the usual provider, neglecting the remaining providers. In addition, the $\mathrm{HHI}$ is generally used to study market structure and measuring market concentration, ${ }^{18)}$ because it measures COC more easily than the other COC indices.

$\frac{\operatorname{Max}\left(n_{1}, n_{2}, \ldots, n_{M}\right)}{N}$

$\mathrm{N}=$ total number of visits

$\mathrm{n}=$ number of visits to each provider

$\mathrm{M}=$ total number of provider

\section{Study Variables: Dependent Variables}

To investigate our hypothesis, we used hospital charges (exchange rate: 1 United States dollar=1,200 Korean won [KRW]) as the dependent variable. Given that the distribution of hospital charges is skewed, we performed a log transformation.

\section{Study Variables: Control Variables}

This study incorporated individual- and hospital-level variables, including age, sex, residential region, patient clinical complexity level (PCCL), diagnostic code, hospital type, organization type, number of beds, number of doctors, and year (a dummy variable). Residential regions were categorized into three groups: metropolitan (Seoul), urban (Daejeon, Daegu, Busan, Incheon, Kwangju, or Ulsan), and rural (otherwise). The hospital type was categorized into three groups: general hospital, hospital, and clinic. The organization type was dichotomized as public and private. The number of beds was categorized into four groups: $\leq 99,100-199,200-299$, and $\geq 300$. The number of doctors was categorized into four groups: $\leq 49,50-99,100-149$, and $\geq 300$.

\section{Statistical Analysis}

In this study, the units of analysis were each individual and each hospital. To investigate whether the COC indices were associated with hospital charges, we used analysis of variance and the generalized estimating equation (GEE) regression model, which accounts for correlation among individuals within each hospital. In the GEE, the proc genmod was used, with link identity and distribution normal. This terminology draws on a common specification of the GEE regression model:

$$
Y_{i t}=\beta_{0}+\beta_{1} \times \operatorname{COC}_{i t}+\beta_{2} \times X_{i t}+e_{i t}
$$

where $Y_{i t}$ is the hospital charges during a time period $t$ for unit $i$.

$Y_{i t}=$ hospital charges

$\beta_{\mathrm{o}}=$ intercept

$C O C_{i t}=$ variable of interest

$X_{\text {it }}=$ covariate

$e_{i t}=$ error term

SAS ver. 9.4 (SAS Institute Inc., Cary, NC, USA) was used in all analyses. All statistical tests were two-tailed, with the null hypothesis being rejected at $\mathrm{P}$-values $<0.05$.

\section{RESULTS}

Of the 247,125 individuals with hypertension included in our study, the mean hospital charge was 17,480 KRW (standard deviation $[\mathrm{SD}]=37,464 \mathrm{KRW}$ ) (Table 1). Table 2 presents the mean value of each COC index, as well as the correlation among the COC measures. The mean values of the COC index, HHI, and MFPC index were 0.848 ( $\mathrm{SD}=0.278), 0.906$ ( $\mathrm{SD}=0.180)$, and 0.930 ( $\mathrm{SD}=0.144)$, respectively. In addition, the Cronbach's $\alpha$ correlation coefficient of the COC measures was 0.921, with the correlation between the HHI and MFPC index being relatively high $(\mathrm{r}=0.984, \mathrm{P}<0.0001)$ (Table 2).

Adjusting for age, sex, residential region, PCCL, diagnostic code, hospital type, organization type, number of beds and doctors, and year, a negative relationship was observed between hospital charges and the COC indices (Table 3). With an increase in one point in the COC measure, hospital charges were $16.3 \%$ lower $(\mathrm{P}<0.0001)$ for the COC index, $10.5 \%$ lower for the HHI, and $13.1 \%$ lower for the MFPC index.

Table 4 presents the results of the subgroup analysis according to hospital type (hospital versus clinic) after adjustment for all confounders. The subgroup analysis by hospital type demonstrated trends that were similar to those that occurred within the entire sample-a significant negative association between COC measures and hospital charges. However, significantly lower hospital charges were observed in the hospital group ( $\mathrm{COC}=33.1 \%$, $\mathrm{HHI}=18.9 \%$, MFPC index $=22.6 \%$ ) than in the clinic group (COC=10.5\%, HHI=7.1\%, MFPC index=8.9\%).

Table 2. General characteristics and correlation between COC indices

\begin{tabular}{|c|c|c|c|c|c|c|c|c|}
\hline \multirow{2}{*}{ Variable } & \multicolumn{2}{|c|}{$\mathrm{COC}$} & \multicolumn{3}{|c|}{ New COC } & \multicolumn{3}{|c|}{ MFPC } \\
\hline & Mean $\pm S D$ & $r$ & Mean $\pm S D$ & $r$ & $P$-value & Mean $\pm S D$ & $r$ & P-value \\
\hline COC indices & $0.848 \pm 0.278$ & & $0.906 \pm 0.180$ & & & $0.930 \pm 0.144$ & & \\
\hline COC & & 1 & & 0.699 & $<0.0001$ & & 0.7 & $<0.0001$ \\
\hline New COC & & & & 1 & & & 0.984 & $<0.0001$ \\
\hline MFPC & & & & & & & 1 & \\
\hline
\end{tabular}

Correlation coefficient (Cronbach's $\alpha=0.921$ ).

COC, continuity of care; MFPC, most frequent provider continuity. 
Table 3. Adjusted association between COC and hospital charges

\begin{tabular}{|c|c|c|c|c|c|c|c|c|c|}
\hline \multirow{2}{*}{ Variable } & \multicolumn{3}{|c|}{$\mathrm{COC}$} & \multicolumn{3}{|c|}{ New COC } & \multicolumn{3}{|c|}{ MFPC } \\
\hline & B & SE & $P$-value & B & SE & P-value & B & SE & P-value \\
\hline Main interesting variable & -0.163 & 0.002 & $<0.0001$ & -0.105 & 0.003 & $<0.0001$ & -0.131 & 0.003 & $<0.0001$ \\
\hline \multicolumn{10}{|l|}{ Individual } \\
\hline \multicolumn{10}{|l|}{ Sex } \\
\hline Male & -0.007 & 0.001 & $<0.0001$ & -0.007 & 0.001 & $<0.0001$ & -0.007 & 0.001 & $<0.0001$ \\
\hline Female & Ref & & & Ref & & & Ref & & \\
\hline \multicolumn{10}{|l|}{ Age $(y)$} \\
\hline$\leq 39$ & 0.051 & 0.004 & $<0.0001$ & 0.057 & 0.004 & $<0.0001$ & 0.057 & 0.004 & $<0.0001$ \\
\hline $40-49$ & 0.000 & 0.003 & 0.966 & -0.001 & 0.003 & 0.779 & -0.001 & 0.003 & 0.745 \\
\hline $50-59$ & 0.001 & 0.002 & 0.640 & -0.001 & 0.002 & 0.705 & -0.001 & 0.002 & 0.664 \\
\hline $60-69$ & 0.018 & 0.003 & $<0.0001$ & 0.016 & 0.003 & $<0.0001$ & 0.016 & 0.003 & $<0.0001$ \\
\hline $70-79$ & 0.030 & 0.003 & $<0.0001$ & 0.028 & 0.003 & $<0.0001$ & 0.028 & 0.003 & $<0.0001$ \\
\hline$\geq 80$ & Ref & & & Ref & & & Ref & & \\
\hline \multicolumn{10}{|l|}{ Residential region } \\
\hline Metropolitan & -0.011 & 0.002 & $<0.0001$ & -0.011 & 0.002 & $<0.0001$ & -0.011 & 0.002 & $<0.0001$ \\
\hline Urban & -0.006 & 0.002 & 0.001 & -0.007 & 0.002 & $<0.0001$ & -0.007 & 0.002 & $<0.0001$ \\
\hline Rural & Ref & & & Ref & & & Ref & & \\
\hline \multicolumn{10}{|l|}{ Patient clinical complexity level } \\
\hline 0 & -0.157 & 0.003 & $<0.0001$ & -0.155 & 0.003 & $<0.0001$ & -0.155 & 0.003 & $<0.0001$ \\
\hline 1 & -0.041 & 0.004 & $<0.0001$ & -0.041 & 0.004 & $<0.0001$ & -0.040 & 0.004 & $<0.0001$ \\
\hline$\geq 2$ & Ref & & & Ref & & & Ref & & \\
\hline \multicolumn{10}{|l|}{ Diagnosed code (110-|15) } \\
\hline Essential hypertension & -0.055 & 0.013 & $<0.0001$ & -0.058 & 0.013 & $<0.0001$ & -0.058 & 0.013 & $<0.0001$ \\
\hline Hypertensive heart disease & -0.046 & 0.013 & 0.000 & -0.050 & 0.013 & 0.000 & -0.050 & 0.013 & 0.000 \\
\hline Hypertensive renal disease & 0.459 & 0.041 & $<0.0001$ & 0.454 & 0.041 & $<0.0001$ & 0.454 & 0.041 & $<0.0001$ \\
\hline Hypertensive heart and renal disease & 0.028 & 0.014 & 0.049 & 0.024 & 0.014 & 0.091 & 0.024 & 0.014 & 0.092 \\
\hline Secondary hypertension & Ref & & & Ref & & & Ref & & \\
\hline \multicolumn{10}{|l|}{ Hospital } \\
\hline \multicolumn{10}{|l|}{ Type } \\
\hline General hospital & 0.145 & 0.012 & $<0.0001$ & 0.151 & 0.012 & $<0.0001$ & 0.151 & 0.012 & $<0.0001$ \\
\hline Hospital & 0.080 & 0.006 & $<0.0001$ & 0.086 & 0.006 & $<0.0001$ & 0.086 & 0.006 & $<0.0001$ \\
\hline Clinic & Ref & & & Ref & & & Ref & & \\
\hline \multicolumn{10}{|l|}{ Organization type } \\
\hline Public & 0.072 & 0.015 & $<0.0001$ & 0.070 & 0.015 & $<0.0001$ & 0.070 & 0.015 & $<0.0001$ \\
\hline Private & Ref & & & Ref & & & Ref & & \\
\hline \multicolumn{10}{|l|}{ Bed } \\
\hline$\leq 99$ & -0.095 & 0.012 & $<0.0001$ & -0.097 & 0.012 & $<0.0001$ & -0.097 & 0.012 & $<0.0001$ \\
\hline $100-199$ & -0.034 & 0.011 & 0.002 & -0.035 & 0.011 & 0.002 & -0.035 & 0.011 & 0.002 \\
\hline $200-299$ & -0.029 & 0.011 & 0.007 & -0.029 & 0.011 & 0.007 & -0.029 & 0.011 & 0.007 \\
\hline$\geq 300$ & Ref & & & Ref & & & Ref & & \\
\hline \multicolumn{10}{|l|}{ Doctor } \\
\hline$\leq 49$ & -0.189 & 0.009 & $<0.0001$ & -0.191 & 0.009 & $<0.0001$ & -0.191 & 0.009 & $<0.0001$ \\
\hline 50-99 & -0.086 & 0.012 & $<0.0001$ & -0.088 & 0.012 & $<0.0001$ & -0.088 & 0.012 & $<0.0001$ \\
\hline $100-149$ & -0.138 & 0.010 & $<0.0001$ & -0.140 & 0.010 & $<0.0001$ & -0.140 & 0.010 & $<0.0001$ \\
\hline$\geq 150$ & Ref & & & Ref & & & Ref & & \\
\hline Year & & & & & & & & & \\
\hline 2002 & 0.038 & 0.003 & $<0.0001$ & 0.045 & 0.003 & $<0.0001$ & 0.045 & 0.003 & $<0.0001$ \\
\hline 2003 & -0.015 & 0.003 & $<0.0001$ & -0.008 & 0.003 & 0.001 & -0.008 & 0.003 & 0.002 \\
\hline 2004 & -0.008 & 0.003 & 0.003 & -0.003 & 0.003 & 0.321 & -0.002 & 0.003 & 0.347 \\
\hline 2005 & 0.022 & 0.002 & $<0.0001$ & 0.026 & 0.002 & $<0.0001$ & 0.027 & 0.002 & $<0.0001$ \\
\hline 2006 & 0.016 & 0.002 & $<0.0001$ & 0.020 & 0.002 & $<0.0001$ & 0.020 & 0.002 & $<0.0001$ \\
\hline 2007 & -0.065 & 0.002 & $<0.0001$ & -0.062 & 0.002 & $<0.0001$ & -0.062 & 0.002 & $<0.0001$ \\
\hline 2008 & -0.102 & 0.002 & $<0.0001$ & -0.100 & 0.002 & $<0.0001$ & -0.099 & 0.002 & $<0.0001$ \\
\hline 2009 & -0.082 & 0.002 & $<0.0001$ & -0.080 & 0.002 & $<0.0001$ & -0.080 & 0.002 & $<0.0001$ \\
\hline 2010 & -0.059 & 0.002 & $<0.0001$ & -0.058 & 0.002 & $<0.0001$ & -0.058 & 0.002 & $<0.0001$ \\
\hline 2011 & -0.033 & 0.002 & $<0.0001$ & -0.031 & 0.002 & $<0.0001$ & -0.031 & 0.002 & $<0.0001$ \\
\hline 2012 & -0.035 & 0.002 & $<0.0001$ & -0.034 & 0.002 & $<0.0001$ & -0.034 & 0.002 & $<0.0001$ \\
\hline 2013 & Ref & & & Ref & & & Ref & & \\
\hline
\end{tabular}

COC, continuity of care; MFPC, most frequent provider continuity; SE, standard error; Ref, reference. 
Table 4. Adjusted association between COC and hospital charges by hospital type

\begin{tabular}{|c|c|c|c|c|c|c|c|c|c|}
\hline \multirow{2}{*}{ Variable } & \multicolumn{3}{|c|}{$\mathrm{COC}$} & \multicolumn{3}{|c|}{ New COC } & \multicolumn{3}{|c|}{ MFPC } \\
\hline & B & SE & P-value & B & SE & P-value & B & SE & P-value \\
\hline Hospital & -0.331 & 0.005 & $<0.0001$ & -0.189 & 0.013 & $<0.0001$ & -0.226 & 0.009 & $<0.0001$ \\
\hline Clinic & -0.105 & 0.001 & $<0.0001$ & -0.071 & 0.001 & $<0.0001$ & -0.089 & 0.002 & $<0.0001$ \\
\hline
\end{tabular}

COC, continuity of care; MFPC, most frequent provider continuity; SE, standard error.

\section{DISCUSSION}

The present study revealed that all COC indices, including the COC index, HHI, and MFPC index, are significantly associated with hospital charges among outpatients with hypertensive diseases. The results provide concrete evidence-based on all the continuity indices-that outpatients with higher COC (strong relationship with hospital or physician) have lower hospital charges, even after controlling for potential confounders, including PCCL-an indicator of severity. Given that hospital charges depend on hospital type, we conducted a subgroup analysis according to hospital type. The analysis showed that, for each index, the direction and significance of the association were the same. That is, the negative association between hospital charges and COC was significant in both hospitals and clinics, regardless of which index was used. Hospitals tend to have more expensive equipment than clinics, and they use a larger variety of assessment tools. Visiting such hospitals consecutively would be costly; this would in turn have an effect on hospital charges. Contrarily, clinics use less expensive assessment tools and examinations to treat patients, meaning a smaller baseline cost and a smaller reduction in clinic charge compared with hospitals.

According to the planned behavior theory, behavioral intentions affect future behaviors. ${ }^{19)}$ Desirable behavioral intentions result in a loyal customer who has "a deeply held commitment to rebuying or re-patronizing health services consistently in the future," ${ }^{20)}$ probably because of greater trust ${ }^{21)}$ and higher satisfaction with their physicians. ${ }^{22)}$ In addition, willingness to go back to the same hospital is affected by cost, service quality, patient satisfaction, perceived value, assurance, and reliability and empathy of the hospitals. Several pieces of evidence have shown that the price of healthcare is a major deterrent to many people who would like to visit hospitals. ${ }^{23,24)}$

Patients with lack of COC are more likely to visit another hospital and switch doctors. Safran et al. ${ }^{25)}$ researched a group of elderly Americans who had received 10 or more years of continuous care and concluded that annual costs in this group were over $\$ 300$ less than in comparable patients who had received 1 year or less with a usual provider of care. Another study found that patients who had continuity with the same hospital had lower resource utilization and healthcare costs. ${ }^{26)} \mathrm{A}$ better understanding of patients will enable policy makers and hospital managers to develop appropriate marketing strategies, attracting new patients and retaining existing customers. Therefore, increasing the perceived value of hospitals by enhancing COC may contribute hospitals' long-term sustainability.
This study had several limitations worth noting, and caution must be taken when interpreting the study's results or attempting to generalize our findings. Firstly, we used the KNHIS cohort sample claims database. When participants were selected for our study, ICD coding was employed. However, the patients' COC may have been partially dependent on the ICD coding of the principal diagnosis, making the study susceptible to error. Since the data had been anonymized, it was difficult to validate the individual ICD codes. Secondly, as this was a large, longitudinal, nationwide sample, there may have been significant heterogeneity in the care provided in the respective hospitals. Thirdly, we could not take into account all factors affecting the COC, such as provider-induced demand, provider behaviors, presence of clinical pathways, and a well-selected care team. Fourthly, we could not identify the individual service provider on the basis of the information in the claims database. Hence, the outpatient healthcare provider was not a physician, but was instead a medical institution. Fifthly, although we used large nationwide sample data (the NHIS-CSD), only insured healthcare costs were considered. Lastly, although we made an effort to resolve reverse-casualties through longitudinal analysis, the possibility still remains.

In conclusion, we measured COC index to reflect patients' COC over 12 years; we also analyzed the relationship between COC and hospital charges among patients with hypertension. Reduced hospital charges were associated with COC. Our study provides empirical evidence that increasing patient COC adds value to the management of chronic conditions, suggesting that long-term and trusting patient-physician relationships are important in reducing healthcare costs.

\section{CONFLICT OF INTEREST}

No potential conflict of interest relevant to this article was reported.

\section{ACKNOWLEDGMENTS}

The present research was conducted by the research fund of Dankook University in 2017.

\section{REFERENCES}

1. Van Walraven C, Oake N, Jennings A, Forster AJ. The association between continuity of care and outcomes: a systematic and critical review. J Eval Clin Pract 2010;16:947-56.

2. Haggerty JL, Reid RJ, Freeman GK, Starfield BH, Adair CE, McKendry 
R. Continuity of care: a multidisciplinary review. BMJ 2003;327:121921.

3. O'Connor PJ, Desai J, Rush WA, Cherney LM, Solberg LI, Bishop DB. Is having a regular provider of diabetes care related to intensity of care and glycemic control? J Fam Pract 1998;47:290-7.

4. Parchman ML, Pugh JA, Noel PH, Larme AC. Continuity of care, selfmanagement behaviors, and glucose control in patients with type 2 diabetes. Med Care 2002;40:137-44.

5. Weiss LJ, Blustein J. Faithful patients: the effect of long-term physicianpatient relationships on the costs and use of health care by older Americans. Am J Public Health 1996;86:1742-7.

6. Lafferty J, Rankin F, Duffy C, Kearney P, Doherty E, McMenamin M, et al. Continuity of care for women with breast cancer: a survey of the views and experiences of patients, carers and health care professionals. Eur J Oncol Nurs 2011;15:419-27.

7. Gray DP, Evans P, Sweeney K, Lings P, Seamark D, Seamark C, et al. Towards a theory of continuity of care. J R Soc Med 2003;96:160-6.

8. McWhinney IR. Continuity of care in family practice: part 2: implications of continuity. J Fam Pract 1975;2:373-4.

9. Wasson JH, Sauvigne AE, Mogielnicki RP, Frey WG, Sox CH, Gaudette $\mathrm{C}$, et al. Continuity of outpatient medical care in elderly men: a randomized trial. JAMA 1984;252:2413-7.

10. Chen CC, Chen SH. Better continuity of care reduces costs for diabetic patients. Am J Manag Care 2011;17:420-7.

11. Gill JM, Mainous AG 3rd. The role of provider continuity in preventing hospitalizations. Arch Fam Med 1998; 7:352-7.

12. Zeithaml VA, Berry LL, Parasuraman A. The behavioral consequences of service quality. J Mark 1996;60:31-46.

13. Ezzati M, Lopez AD, Rodgers A, Vander Hoorn S, Murray CJ; Comparative Risk Assessment Collaborating Group. Selected major risk factors and global and regional burden of disease. Lancet 2002;360:1347-60.

14. Lee J, Lee JS, Park SH, Shin SA, Kim K. Cohort profile: the National
Health Insurance Service-National Sample Cohort (NHIS-NSC), South Korea. Int J Epidemiol 2017;46:e15.

15. Bice TW, Boxerman SB. A quantitative measure of continuity of care. Med Care 1977;15:347-9.

16. Zwanziger J, Melnick GA, Simonson L. Differentiation and specialization in the California hospital industry 1983 to 1988 . Med Care 1996;34:361-72.

17. Given CW, Branson M, Zemach R. Evaluation and application of continuity measures in primary care settings. J Community Health 1985;10:22-41.

18. Lindlbauer I, Schreyogg J. The relationship between hospital specialization and hospital efficiency: do different measures of specialization lead to different results? Health Care Manag Sci 2014;17:365-78.

19. Ajzen I. The theory of planned behavior. Organ Behav Hum Decis Process 1991;50:179-211.

20. Oliver RL. Whence consumer loyalty? J Mark 1999;63:33-44.

21. Mainous AG 3rd, Baker R, Love MM, Gray DP, Gill JM. Continuity of care and trust in one's physician: evidence from primary care in the United States and the United Kingdom. Fam Med 2001;33:22-7.

22. Parchman ML, Burge SK. The patient-physician relationship, primary care attributes, and preventive services. Fam Med 2004;36:22-7.

23. Asenso-Okyere WK, Anum A, Osei-Akoto I, Adukonu A. Cost recovery in Ghana: are there any changes in health care seeking behaviour? Health Policy Plan 1998;13:181-8.

24. Pokhrel S, Hidayat B, Flessa S, Sauerborn R. Modelling the effectiveness of financing policies to address underutilization of children's health services in Nepal. Bull World Health Organ 2005;83:338-44.

25. Safran DG, Montgomery JE, Chang H, Murphy J, Rogers WH. Switching doctors: predictors of voluntary disenrollment from a primary physician's practice. J Fam Pract 2001;50:130-6.

26. Cornelius LJ. The degree of usual provider continuity for African and Latino Americans. J Health Care Poor Underserved 1997;8:170-85. 